\title{
Integrated Approach for Prediction of Hot Tearing
}

\author{
SUYITNO, W.H. KOOL, and L. KATGERMAN
}

Shrinkage, imposed strain rate, and (lack of) feeding are considered the main factors that determine cavity formation or the formation of hot tears. A hot-tearing model is proposed that will combine a macroscopic description of the casting process and a microscopic model. The micromodel predicts whether porosity will form or a hot tear will develop. Results for an Al-4.5 pct $\mathrm{Cu}$ alloy are presented as a function of the constant strain rate and cooling rate. Also, incorporation of the model in a finite element method (FEM) simulation of the direct-chill (DC) casting process is reported. The model shows features well known from literature such as increasing hot-tearing sensitivity with increasing deformation rate, cooling rate, and grain size. Similar trends are found for the porosity formation as well. The model also predicts a beneficial effect of applying a ramping procedure during the start-up phase, which is an improvement in comparison with earlier findings obtained with alternative models. In principle, the model does not contain adjustable parameters, but several parameters are not well known. A full quantitative validation not only requires detailed casting trials but also independent determination of some thermophysical parameters of the semisolid mush.

DOI: $10.1007 / \mathrm{s} 11661-009-9941-\mathrm{y}$

(C) The Author(s) 2009. This article is published with open access at Springerlink.com

\section{INTRODUCTION}

HoT tears are cracks that initiate in the mushy zone. These cracks are characterized by intergranular fracture and a smooth fracture surface due to the existence of a liquid phase in the interdendritic region during cracking. ${ }^{[1]}$ Hot tearing is one of the crucial problems encountered during the direct-chill (DC) casting process. The occurrence of hot tears determines the productivity during the process. These solidification defects have been understood for a long time, but a quantitative prediction of their occurrence is still underdeveloped.

In general, the solidification processes proceed in four steps that reflect the morphological development and interaction, namely: (1) the nucleated crystals float freely and the macroscopic behavior is close to the liquid behavior; (2) the nuclei are close and tend to attach to each other to form a porous network and the solidification shrinkage strain is easily counteracted by the liquid flow and solid arrangement; (3) the deformation of the solidified body caused by the solidification shrinkage and external strains is not fully counteracted by the liquid flow and solid movement, so that solidification defects such as hot tears and porosity are usually initiated; and (4) the grains are strongly interconnected, so that deformation of the solidified body will not result in further defects.

SUYITNO, Associate Professor, is with the Casting and Solidification Technology (CASTEC) Laboratory, Department of Mechanical and Industrial Engineering, Gadjah Mada University, Yogyakarta, Indonesia. Contact e-mail: suyitno@ugm.ac.id W.H. KOOL, Associate Professor, and L. KATGERMAN, Professor, are with Department of Materials Science and Engineering, Faculty $3 \mathrm{mE}$, Delft University of Technology, 2628 CD Delft, The Netherlands.

Manuscript submitted May 13, 2008.

Article published online August 19, 2009
Quantitative prediction of hot tearing is not easy because of the complex interplay between macroscopic and microscopic phenomena. Prediction of hot tearing during DC casting is based on two steps, namely modeling of the thermomechanical behavior during solidification $^{[2-4]}$ and the implementing of hot-tearing criteria into this model. ${ }^{[5-10]}$ The first step uses constitutive equations to describe the thermomechanical modeling, to calculate stresses and strains in the billet. Computed stresses or strains indicate the hot-tearing tendency. In the second step, the results of the first step are used as input into a hot-tearing criterion.

Several mechanisms of hot tearing have recently been reviewed ${ }^{[1]}$ and a recent article outlines the requirements for a modern hot-tearing model and a criterion based on this model as well as the future development of hottearing research in terms of mechanisms of hot-crack nucleation and propagation. ${ }^{[11,12]}$ Various criteria that might enable the prediction of hot tears have been proposed. ${ }^{[13-20]}$ These criteria can be classified into those based on nonmechanical aspects such as feeding behavior, ${ }^{[13-15]}$ those based only on mechanical aspects, ${ }^{[16-18]}$ and those that combine these features. ${ }^{[19,20]}$

Approaches based on nonmechanical criteria ${ }^{[13-15]}$ put emphasis on the feeding properties in the mush and assume that the second and third stages of solidification play the main role in the formation of a hot tear. In contrast, the mechanical criteria ${ }^{[16-18]}$ emphasize the importance of the strengths and strains developed in the third and fourth stages of the solidification. Some approaches ${ }^{[19,20]}$ combine these mechanical and nonmechanical methods for the prediction of hot tearing.

A comprehensive evaluation of existing hot-tearing criteria for DC casting of aluminum billets is reported in References 8 through 10 . In the assessment of various criteria for hot tearing, it is found that the RDG criterion, ${ }^{[19]}$ which combines mechanical and feeding 
conditions, had the greatest potential with respect to the other criteria, but it did not predict cracking for the practical conditions in which cracking will not occur. ${ }^{[10]}$

Therefore, in this study, a hot-tearing model is derived based on cavity formation when there is insufficient feeding during solidification. The feeding during solidification is incorporated using a transient mass balance equation. The flow behavior of the semisolid state has been included in order to model the mechanical response of the semisolid body. The cavity formed becomes a hot tear when a critical dimension is achieved; otherwise, porosity will result. The possibility of the formation of microporosity is not found for other models.

The proposed model is applied in two types of simulation. First, the porosity growth, hot-cracking sensitivity, and developed stress in the mush are calculated as a function of several parameters, using as constant parameters the strain rate and cooling rate. Second, the proposed model is incorporated in a finite element method (FEM) simulation of DC casting an Al-4.5 pet $\mathrm{Cu}$ billet. The hot-cracking sensitivities are calculated as a function of several parameters and are compared with those from the RDG criterion. ${ }^{[19]}$

\section{PHYSICAL MODEL}

Solidification is initiated by the formation of nuclei that grow to form a dendritic structure. In the model, it is assumed that the microstructure is equiaxed. The floating grains grow, coarsen, and reach the coherency point at which the dendrites touch each other. Cavities are formed at triple junctions between the grains. At and beyond the coherency point, stresses can be transmitted through the dendritic network. At the coherency point, the volume difference due to the thermal shrinkage and imposed deformation can be filled with liquid metal. During further solidification, the liquid network becomes interrupted and liquid pockets become isolated. Permeability becomes low and the dendritic network becomes strong. The liquid flow and afterfeeding of the volume difference becomes suppressed.

During complete solidification, there are three possibilities. The first is that the liquid flow and afterfeeding (or even the solid diffusion after complete solidification) are sufficient to counteract thermal shrinkage and imposed deformation and, therefore, cavities are not formed and a fully dense microstructure is found. The second is that the liquid flow and afterfeeding are insufficient to counteract thermal shrinkage and imposed deformation and, therefore, cavities are formed, leading to a microstructure containing porosity. The third is that the cavity dimension reaches a critical value, which leads to the formation of a hot crack. The critical cavity dimension that leads to crack is determined by using Griffith's approach, ${ }^{[21,22]}$ considering that local conditions are brittle. This approach is used considering the appearance of hot-tear surface that does not show evidence of plastic deformation. ${ }^{[11]}$

Experimental observations indicate that hot tears are generally found in the center of the billet and have a starlike form (visible in the billet cross section). ${ }^{[2,9,23]}$ This means that stresses and strains in the billet cross section are dominant. To simplify the complex threedimensional (3-D) conditions of solidification during casting, it is therefore assumed that the stress, strain, and strain rates imposed by the mush are acting in the plane normal to the casting direction. Feeding takes place in the casting direction. The stress, strain, and strain rate are calculated by a FEM. The feeding behavior is represented by Feurer's approach, which is derived from Darcy's law.

\section{MATHEMATICAL MODEL}

The model that enables the prediction of the formation of microporosity or hot tears during DC casting consists of a micromodel that accounts for the local mechanical and feeding properties of the mush, coupled with a macromodel of the DC casting process (for example, by FEM simulation).

The proposed model is illustrated in detail in Figure 1. The input data for the model provided by the macromodel are the temperature $(T)$, cooling rate $(\dot{T})$, and strain rate $(\dot{\varepsilon})$. The solidification model links the temperature with the solid/liquid fraction, which is needed in the constitutive model of the mush and in the feeding model. The contribution of feeding $|f e|$ is compared with the local strain rate $f r$, resulting from shrinkage and deformation. Above the coherency temperature, only a shrinkage term contributes to $\mathrm{fr}$, and $\mathrm{fr}$ will be smaller than $|f e|$. Below the coherency temperature, deformation forces will contribute to $\mathrm{fr}$.

If at any moment during the solidification $f r-|f e|$ becomes larger than a critical parameter $\zeta_{\text {crit }}$, a cavity is formed. The parameter $\zeta_{\text {crit }}$ accounts for the nucleation

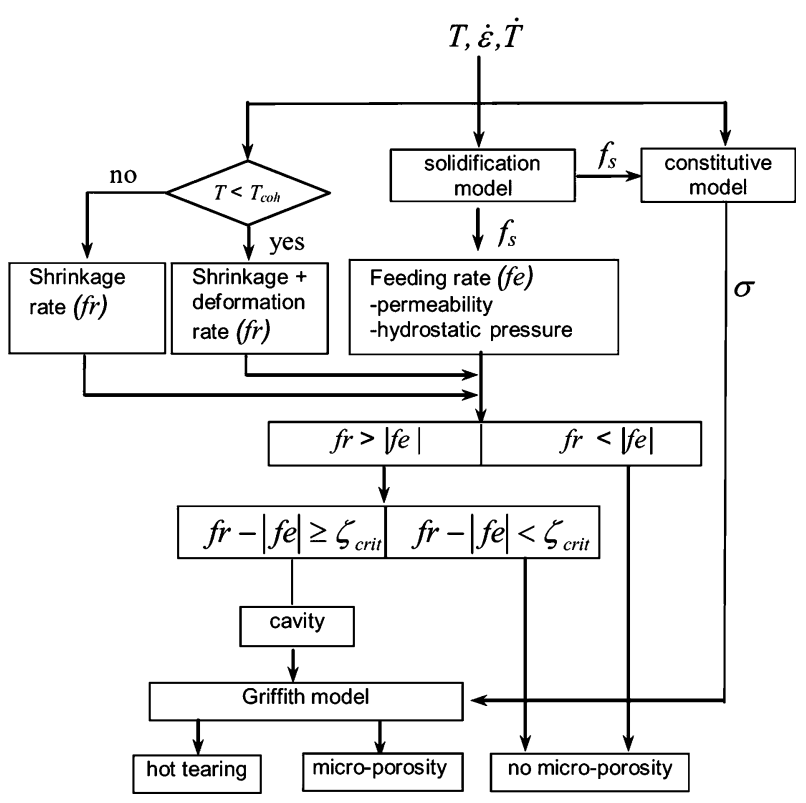

Fig. 1-Schematic representation of the model: $f r$ is the shrinkage + deformation rate and $f e$ is the feeding rate. 
of the cavity. In the simulation, $\zeta_{\text {crit }}$ is taken equal to zero, i.e., it is assumed that a nucleation effect of the cavity can be neglected. In the case in which the diameter of the cavity exceeds a critical diameter determined by Griffith's model, the cavity will result in a hot tear. In the Griffith's model, the critical diameter depends on the stress in the mush. The stress $\sigma$ follows from the constitutive model. Based on this, three possibilities arise: a dense microstructure without microporosity, the formation of microporosity, or the formation of hot tears.

\section{A. Solidification Model}

In the solidification model, the liquid fraction $f_{l}$ as a function of temperature is determined using the following equation: ${ }^{[24]}$

$$
\begin{aligned}
& f_{l}=\frac{1}{1-2 \alpha_{s}^{*} k}\left[\left(\frac{T_{m}-T}{T_{m}-T_{l}}\right)^{\frac{1-2 \alpha_{s}^{*} k}{k-1}}\right] \text { and } \\
& \alpha_{s}^{*}=\alpha_{s}\left[1-\exp \left(-\frac{1}{\alpha_{s}}\right)\right]-\frac{1}{2} \exp \left(-\frac{1}{2 \alpha_{s}}\right)
\end{aligned}
$$

where $T_{m}$ is the melting temperature of the pure metal, $T_{l}$ is the liquidus temperature, $T$ is the temperature, $k$ is the partition coefficient, $\alpha_{s}$ is the back-diffusion coefficient, and $\alpha_{s}^{*}$ is the modified dimensionless solid-state back-diffusion parameter.

\section{B. Constitutive Model of the Mush}

The stress developed in the mush is computed using a constitutive model that will depend on the solid fraction, strain rate, and temperature. Here, we will use the following expression: ${ }^{[20]}$

$$
\sigma=\sigma_{o} \exp \left(\beta f_{s}\right) \exp \left(\frac{m Q}{R T}\right)(\dot{\varepsilon})^{m}
$$

where $Q$ is the activation energy given by the solid phase deformation behavior, $m$ is the strain rate sensitivity coefficient, $R$ is the gas constant, $\sigma_{o}$ and $\beta$ are material constants, and $\dot{\varepsilon}$ is the strain rate.

\section{Shrinkage, Deformation, and Feeding Terms}

A transient mass conservation equation is applied to a 3-D element in the solidifying billet of which a complete derivation is shown in the Appendix. It reads:

$$
\frac{\rho_{s}}{\rho_{l}} \frac{\partial f_{v}}{\partial t}=-\left(\frac{\rho_{s}}{\rho_{l}}-1\right) \frac{\partial f_{l}}{\partial t}+\left(\frac{\rho_{s}}{\rho_{l}}\right) \dot{\varepsilon}+f e
$$

where $\dot{\varepsilon}$ and $f e$ are the strain rate and feeding rate, respectively, $f_{s}, f_{l}$, and $f_{v}$ are the solid, liquid, and cavity fraction, respectively, and $\rho_{s}$ and $\rho_{l}$ are the densities of the solid and liquid, respectively.

The contribution of shrinkage and deformation $\mathrm{fr}$ reads:

$$
f r=-\left(\frac{\rho_{S}}{\rho_{l}}-1\right) \frac{\partial f_{l}}{\partial t}+\left(\frac{\rho_{S}}{\rho_{l}}\right) \dot{\varepsilon}
$$

The feeding term $f e$ is based on the interdendritic flow in a mush that uses the Carman-Kozeny approximation $^{[25,26]}$ and reads as follows:

$$
\begin{gathered}
f e=K \frac{P_{s}}{\eta L^{2}} \\
K=\frac{\lambda^{2}}{180} \frac{\left(1-f_{s}\right)^{3}}{f_{s}^{2}} \\
P_{s}=P_{o}+P_{m}-P_{c} \\
P_{c}=\frac{4 \gamma_{s}}{\lambda}
\end{gathered}
$$

where $K$ is the permeability, $\lambda$ the is secondary dendritic arm spacing, $\eta$ is the viscosity of the liquid phase, $L$ is the length of the porous network, $\gamma_{s}$ is the solid-liquid interfacial energy, $P_{s}$ is the effective feeding pressure, and $P_{o}, P_{m}$, and $P_{c}$ are the atmospheric, metallostatic, and capillary pressure, respectively. In the model, $\lambda$ and $P_{c}$ are independent of the temperature. The $L$ is taken as the length of mush from the coherency until the end of solidification. For the feeding term $|f e|$, only the $z$ direction (casting direction) is taken into account. Under compressive conditions, $P_{s}$ is negative, resulting in a negative value of $f e$.

\section{Cavity Nucleation}

If $f r<|f e|$ (Eqs. [4] and [5]), feeding will be sufficient and the actual volumetric flow rate per unit volume will be equal to the shrinkage and deformation rate.

If $f r>|f e|$, feeding will be insufficient and a cavity will form and grow if $f r-|f e| \geq \zeta_{\text {crit }}$, where $\zeta_{\text {crit }}$ is a term describing the nucleation of the cavity. The $\zeta_{\text {crit }}$ can be expressed in a critical pressure $\left(P_{\text {crit }}\right)$ for cavity nucleation, as follows:

$$
\zeta_{\text {crit }}=K \frac{P_{\text {crit }}}{\eta L^{2}}
$$

The value of the critical depression pressure has to be determined from the experimental data. A value $2 \mathrm{kPa}$, such as is used in Reference 5, will result in a small value of $\zeta_{\text {crit }}$. Therefore, in this calculation, $\zeta_{\text {crit }}$ is taken as equal to zero and it is assumed that $f r-|f e|$ is always equal to the cavity volume.

If the condition for the formation of a cavity is fulfilled, parameter $\partial f_{v} / \partial t$ is a measure for cavity growth. The fraction $f_{v}$ and the diameter $d$ of the cavity are determined by

$$
f_{v}=\int_{t_{\text {liq }}}^{t} \frac{\partial f_{v}}{\partial t} d t
$$

$$
d=\left(\frac{3}{2 \pi} f_{v} V_{\text {char }}\right)^{1 / 3}
$$




$$
V_{\text {char }}=C d_{g}^{3}
$$

where $t_{\text {liq }}$ is the time that corresponds with the start of solidification, $V_{\text {char }}$ is the characteristic volume of the local geometry (cavity and grains), and $d_{g}$ is the diameter of the grain. The term $C$ is a packing parameter accounting for the packing of the grains. It is equal to $2 \sqrt{2}$ for fcc and $\frac{8}{3 \sqrt{3}}$ for bcc packing.

In Griffith's approach, ${ }^{[21,22]}$ the relation between the critical cavity length $a_{\text {crit }}$ and the stress $\sigma$ in the mush for the cavity to propagate as crack is expressed in Eq. [13]:

$$
a_{\text {crit }}=4 \gamma_{s} \frac{E}{\pi \sigma^{2}}
$$

where $\gamma_{e}$ is the surface tension of the liquid metal and $E$ is the Young's modulus of the mush. The stress in the mush is given by Eq. [2].

To account for the irregularity of the cavity shape, a constant $C_{1}$ is introduced:

$$
a=C_{1} d
$$

which relates the longest cavity length with the diameter of a spherical cavity. The $C_{1}$ is larger than or equal to 1 . From Eqs. [11], [12], and [14], $a$ is calculated. If $a \geq a_{\text {crit }}$, a crack will develop.

\section{E. Hot-Cracking Sensitivity}

The hot-cracking susceptibility (HCS) is defined by

$$
H C S=\frac{a_{\text {crit }}}{a}
$$

Used qualitatively, this definition means an increasing susceptibility for hot cracking with increasing value. Used quantitatively, it means that if the hot-cracking sensitivity is higher than 1 , a hot tear will develop.

\section{SIMULATION}

\section{A. Simulation with Constant Parameters}

A part of the calculations in the model was performed for constant $\dot{\varepsilon}, \dot{T}$, and $L$, where the strain rates $\dot{\varepsilon}$ were varied from $10^{-5}$ to $10^{-3} \mathrm{~s}^{-1}$, the cooling rates $\dot{T}$ were varied from 0.1 through $10 \mathrm{~K} / \mathrm{s}$, and $L$ was taken as $0.1 \mathrm{~m}$. Simulation was done for an Al-4.5 pet $\mathrm{Cu}$ alloy. The parameters used in the calculation are given in Table I. Further, it is assumed that the deformation was only in the cross section of the billet.

\section{B. Simulation with FEM Modeling of DC Casting Billet}

Another part of the calculations in the model was performed after incorporating the model in an FEM code. The DC casting of an Al-4.5 pct $\mathrm{Cu}$ alloy billet with a $100-\mathrm{mm}$ radius and $1000-\mathrm{mm}$ length is simulated. The computation procedure is similar to that performed in Reference 4. An axis-symmetric model is used in this work. Due to the symmetry, only a half section of the billet and bottom block needs to be modeled. For the
Table I. Parameters Used in Calculations and the Appropriate References

\begin{tabular}{llll}
\hline Parameter & Value & Unit & Reference \\
\hline$\alpha_{s}$ & 0.01 & - & 19 \\
$k$ & 0.14 & - & 24 \\
$T_{m}$ & 933 & $\mathrm{~K}$ & 35 \\
$\sigma_{o}$ & 4.5 & $\mathrm{~Pa}$ & 20 \\
$m$ & 0.26 & - & 20 \\
$\alpha$ & 10.2 & $\mathrm{~kJ} / \mathrm{mol}^{2}$ & 20 \\
$Q$ & 160 & $\mathrm{MPa}$ & 20 \\
$E$ & 40 & $\mathrm{~J} / \mathrm{m}^{2}$ & 20,33 \\
$\gamma_{s}$ & 0.84 & $\mathrm{~kg} / \mathrm{m}^{3}$ & 35 \\
$\rho_{s}$ & 2790 & $\mathrm{~kg} / \mathrm{m}^{3}$ & 35 \\
$\rho_{l}$ & 2480 & $\mathrm{~m}$ & 35 \\
$\lambda$ & $8 \cdot 10^{-5}$ & $\mathrm{~Pa} \cdot \mathrm{s}$ & - \\
$\eta$ & 0.0013 & $\mathrm{~m}$ & 35 \\
$d_{g}$ & $5 \cdot 10^{-4}$ & - & - \\
$C$ & 1 & - & - \\
\hline
\end{tabular}

simulation, a coupled computation of the stress and the temperature fields is applied using four-node rectangular elements with four Gaussian integration points.

In the simulation, the ingot remains in a stationary position, while the mold and the impingement point of the water flow move upward with a velocity equal to the casting speed. The continuous feeding of liquid metal is implemented by activating horizontal layers of elements incrementally. The computational domain is shown in Figure 2. After every time step, the HCS is computed at every node.

Computation is performed for two phases in the billet. The first phase is distant from the beginning of the billet (start-up phase) by 0 to $400 \mathrm{~mm}$. Four casting conditions, denoted 1 through 4 , are applied in the computation to calculate the hot-tearing tendency as a function of the axial position. The casting modes are shown in Figure 3. The second region is at a distance of $750 \mathrm{~mm}$ from the beginning of the billet (steady-state phase). The casting speeds selected were constant and were equal to 120,150 , and $180 \mathrm{~mm} / \mathrm{min}$. Here, the hottearing tendency is calculated as a function of the radial position in the billet. Most of the parameters used in the incorporation with FEM modeling of DC casting a billet are also given in Table I. However, three parameters were adjusted and are given in Table II. These adjustment parameters were taken from the experimental data. ${ }^{[9]}$

\section{RESULTS}

\section{A. Simulation with Constant Parameters}

In the simulation with a constant strain rate, cooling rate, and length of porous network, the main emphasis was on the calculation of the feeding rate or mechanical parameters as a function of the solid fraction.

\section{Cavity nucleation}

In Section III, the quantities $|f e|$ and $f r$, which are the volume fraction per unit time fed by the liquid flow and 


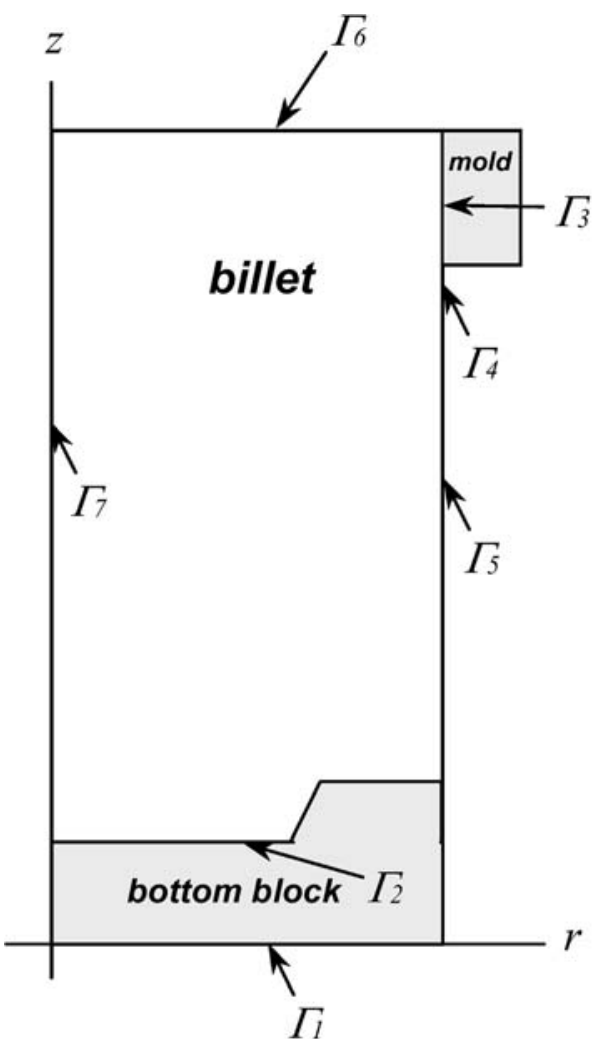

Fig. 2-Computational domain of the DC-cast billet. The $\Gamma_{1}$ through $\Gamma_{7}$ correspond with boundary conditions defined in Ref. 4.

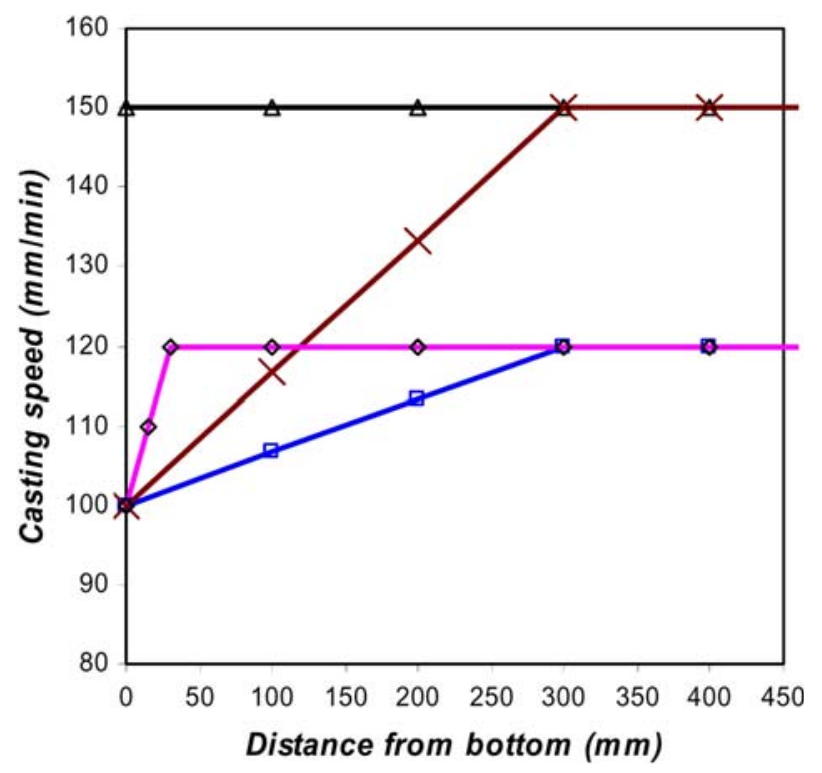

Fig. 3- Casting modes applied for simulation of the start-up phase of DC casting. Casting conditions: $(\diamond) 1,(\square) 2,(\Delta) 3$, and (x) 4 .

the volume fraction per unit time related to shrinkage and imposed deformation, respectively, were introduced. Figure 4 shows the value of $|f e|$ and $f r$ as a function of the solid fraction for various strain rates and cooling rates. The value of $f r$ becomes lower at high
Table II. Modified Parameters Used in the Calculations of DC Casting

\begin{tabular}{lllc}
\hline Parameter & Value & Unit & Reference \\
\hline$E$ & 10 & GPa & - \\
$\lambda$ & $1 \cdot 10^{-5}$ & m & 9 \\
$d_{g}$ & $3 \cdot 10^{-4}$ & m & 9 \\
\hline
\end{tabular}

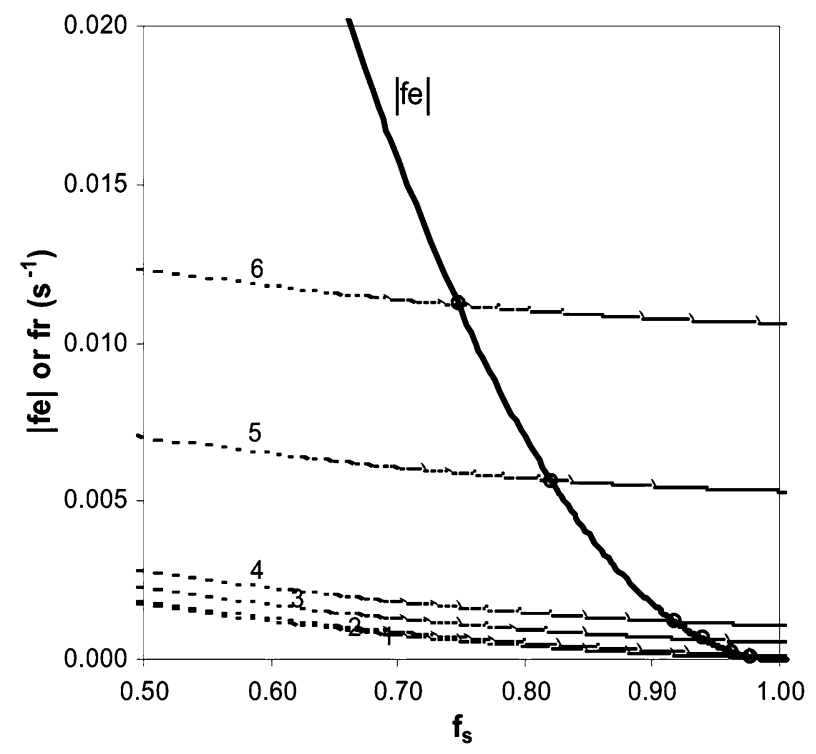

(a)

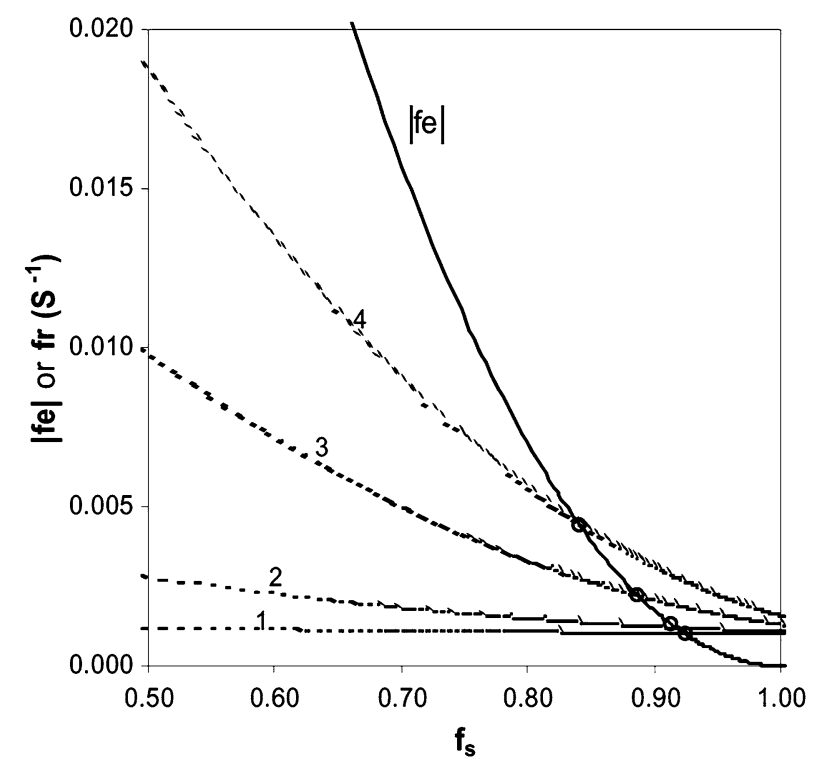

(b)

Fig. 4-Parameters $f r$ (1 through 6) and $|f e| v s$ solid fraction. (a) Effect of strain rate at cooling rates of $1 \mathrm{~K} / \mathrm{s}$; strain rates: (1) $10^{-5} \mathrm{~s}^{-1}$, (2) $10^{-4} \mathrm{~s}^{-1}$, (3) $5 \cdot 10^{-4} \mathrm{~s}^{-1}$, (4) $10^{-3} \mathrm{~s}^{-1}$, (5) $5 \cdot 10^{-3} \mathrm{~s}^{-1}$, and (6) $10^{-2} \mathrm{~s}^{-1}$. (b) Effect of cooling rate for strain rate of $5 \cdot 10^{-4} \mathrm{~s}^{-1}$; cooling rates: (1) $0.1 \mathrm{~K} / \mathrm{s}$, (2) $1 \mathrm{~K} / \mathrm{s}$, (3) $5 \mathrm{~K} / \mathrm{s}$, and (4) $10 \mathrm{~K} / \mathrm{s}$. The $|f e|$ is independent of strain rate or cooling rate.

solid fractions, because the shrinkage term is dominant and $\partial f_{l} / \partial T$ decreases with increasing solid fraction. The value of $f r$ increases with an increasing strain rate or 
cooling rate, according to Eq. [4]. The value of $|f e|$ decreases as a function of the solid fraction, because feeding becomes more difficult at higher solid fractions. For the effect of the strain rate or cooling rate on the $|f e|$, microstructural parameters are the most influential factor for the value of $|f e|$. Because in this calculation these parameters are kept constant, there is no effect of the strain rate or cooling rate on $|f e|$.

The intersection points of the $|f e|$ and $f r$ curves, indicated in the figure, give the solid fractions at which the growth of cavities will begin. It is seen that growth occurs earlier (i.e., at lower fractions of solid) for higher

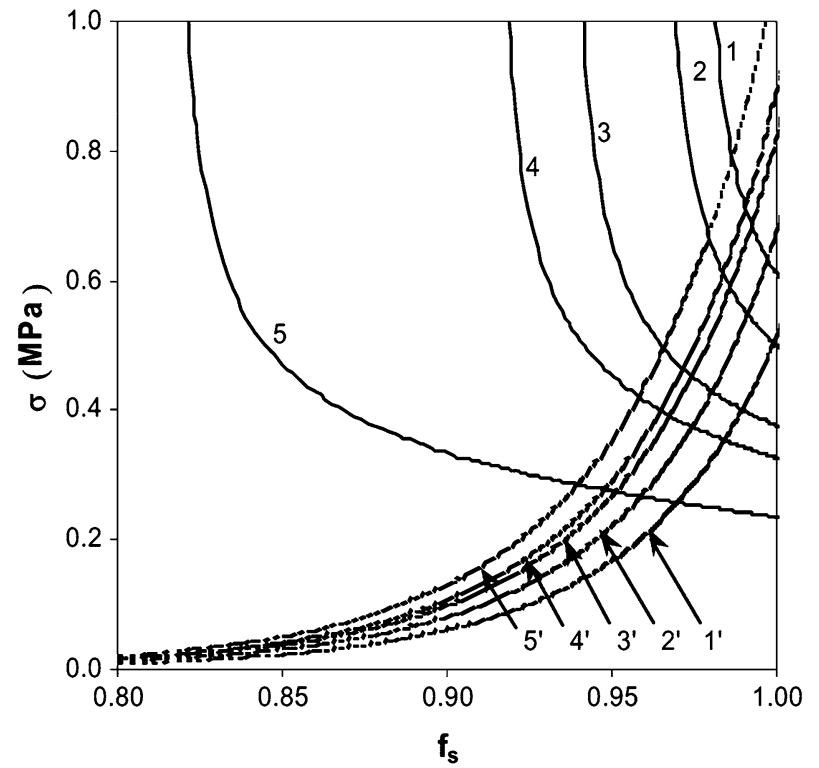

(a)

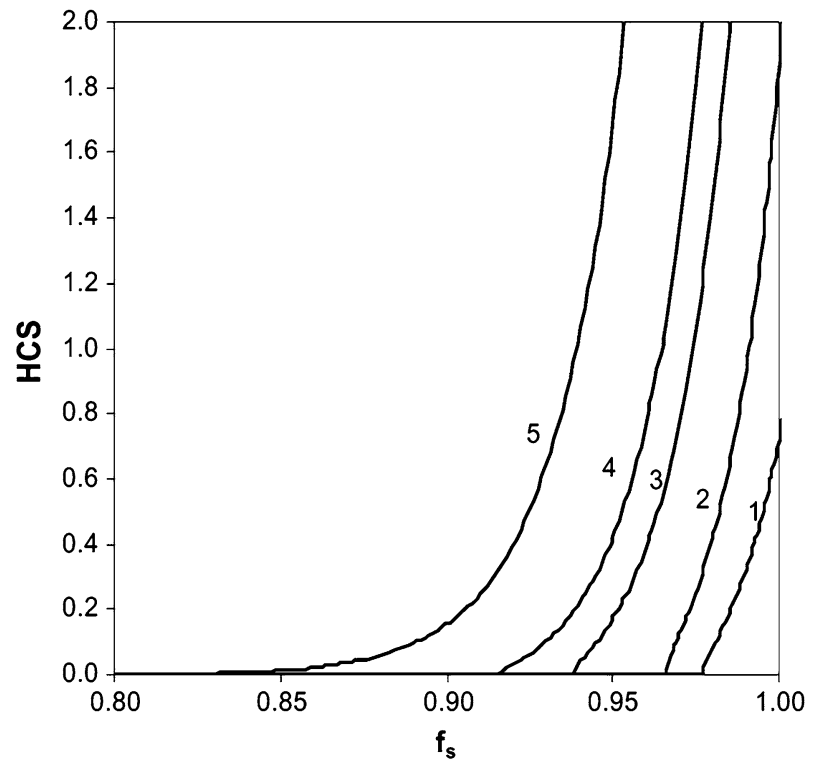

(b)

Fig. 5-(a) Developed stress and critical stress and (b) HCS vs solid fraction for various strain rates; cooling rate: $1 \mathrm{~K} / \mathrm{s}$. Developed stress ( $1^{\prime}$ through $\left.5^{\prime}\right)$; critical stress and HCS (1 through 5). Strain rates: (1) $10^{-5} \mathrm{~s}^{-1}$, (2) $10^{-4} \mathrm{~s}^{-1}$, (3) $5 \cdot 10^{-4} \mathrm{~s}^{-1}$, (4) $10^{-3} \mathrm{~s}^{-1}$, and (5) $5 \cdot 10^{-3} \mathrm{~s}^{-1}$ strain rates and cooling rates. This is evident, because the amount of volume per unit time, which should be fed, increases with higher strain rates and cooling rates.

\section{Porosity and Hot Tearing}

Figures 5 and 6 present both the stress developed in the mush as a function of solid fraction (calculated from Eq. [2]) and the critical stress in the Griffith's approach, i.e., the stress calculated from Eq. [13] for a cavity, with length $a$ calculated from Eq. [14]. In the figure, the HCS is also given (Eq. [15]). Developed stress and HCS increase for an increasing solid fraction and strain rate.

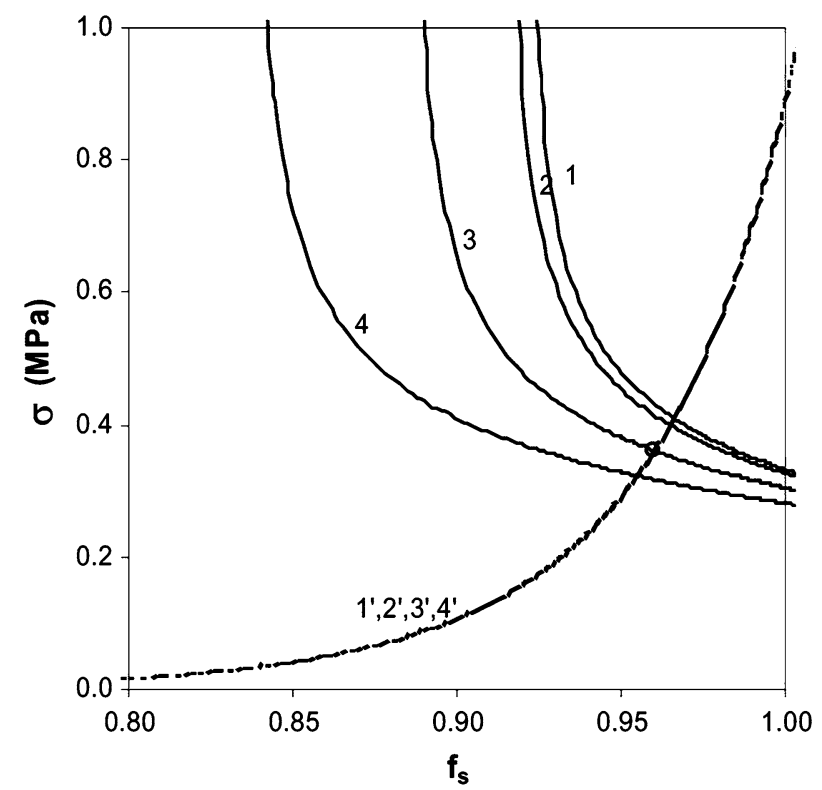

(a)

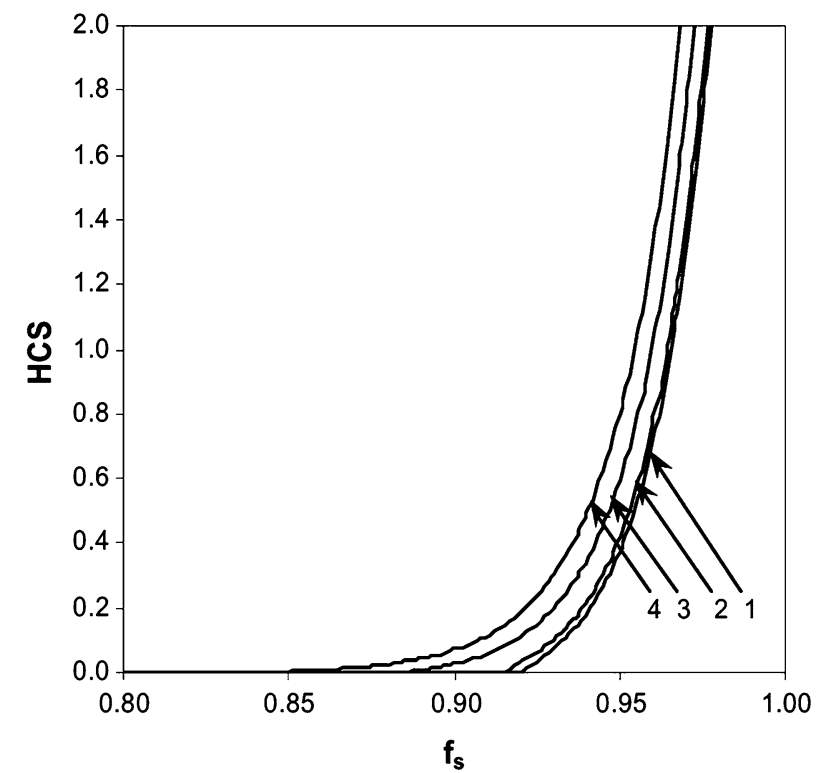

(b)

Fig. 6-(a) Developed stress and critical stress and (b) HCS vs solid fraction for various cooling rates; strain rate: $5 \cdot 10^{-4} \mathrm{~s}^{-1}$. Developed stress ( $1^{\prime}$ through $\left.4^{\prime}\right)$; critical stress and HCS (1 through 4$)$. Cooling rates: (1) $0.1 \mathrm{~K} / \mathrm{s}$, (2) $1 \mathrm{~K} / \mathrm{s}$, (3) $5 \mathrm{~K} / \mathrm{s}$, and (4) $10 \mathrm{~K} / \mathrm{s}$. 


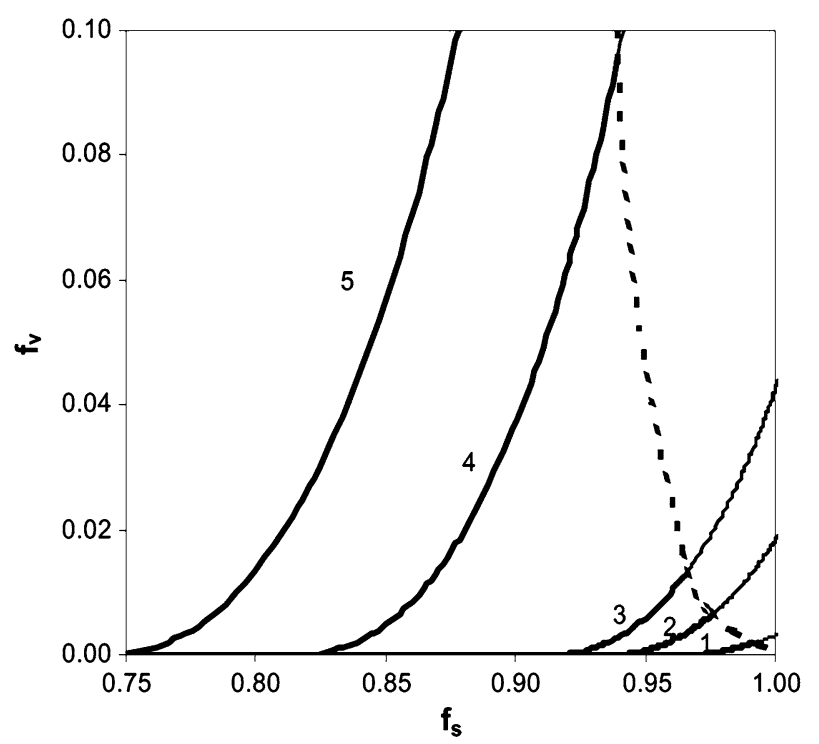

(a)

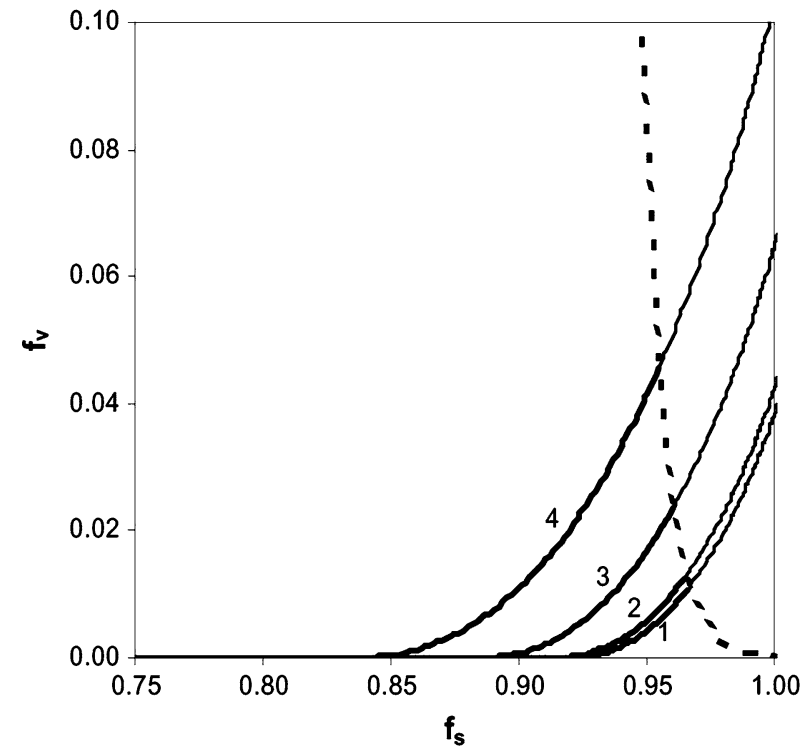

(b)

Fig. 7-Cavity fraction $v s$ fraction solid. Dashed curve indicates start of tear development. (a) Effect of strain rate at cooling rate of $1 \mathrm{~K} / \mathrm{s}$; strain rates: (1) $10^{-5} \mathrm{~s}^{-1}$, (2) $10^{-4} \mathrm{~s}^{-1}$, (3) $5.10^{-4} \mathrm{~s}^{-1}$, (4) $10^{-3} \mathrm{~s}^{-1}$, and (5) $5 \cdot 10^{-3} \mathrm{~s}^{-1}$. (b) Effect of cooling rate for strain rate of $5 \cdot 10^{-4} \mathrm{~s}^{-1}$; cooling rates: (1) $0.1 \mathrm{~K} / \mathrm{s}$, (2) $1 \mathrm{~K} / \mathrm{s}$, (3) $5 \mathrm{~K} / \mathrm{s}$, and (4) $10 \mathrm{~K} / \mathrm{s}$.

The HCS increases for an increasing cooling rate. The intersection points of the developed stress and the critical stress for cavity growth are assumed to be the transition from development of microporosity to the initiation of hot tearing.

Figure 7 shows the cavity fraction $f v$ as a function of solid fraction for the various strain rates and cooling rates. Cavities are initiated at the solid fraction at which $f v$ starts to deviate from zero. These points correspond with the intersection points found in Figure 4 and indicate the beginning of the formation of porosity. In addition, the intersection points found in Figures 5 and 6 are indicated in Figure 7. They are connected by a dashed line, which indicates the fraction solid values at

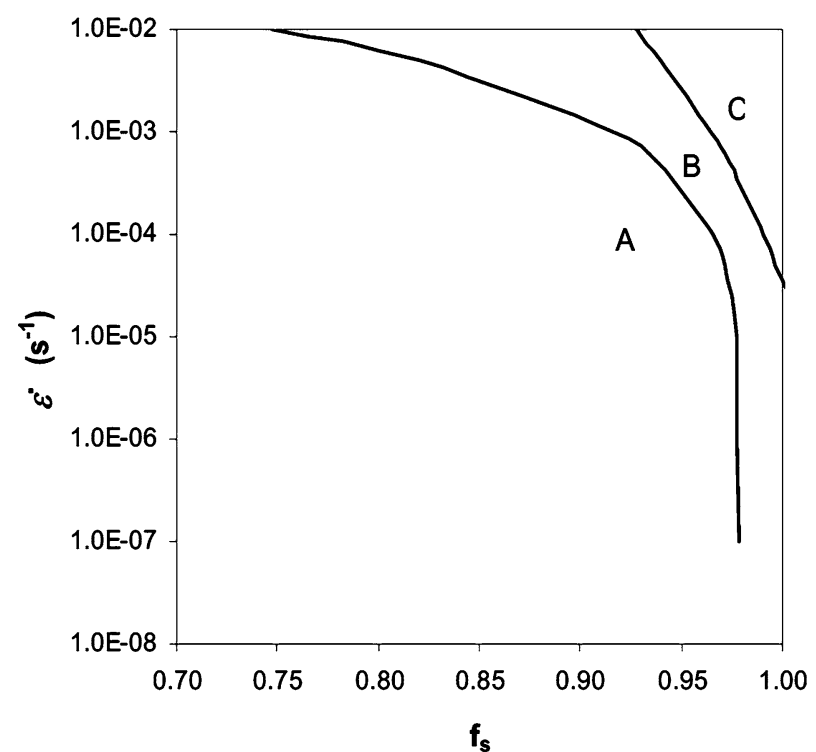

(a)

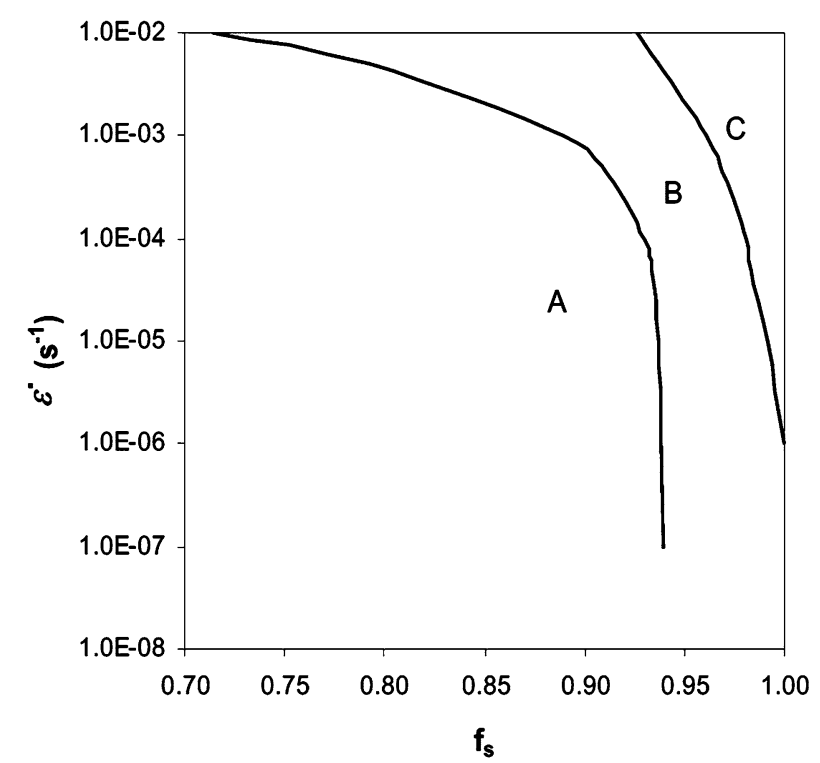

(b)

Fig. 8-Three regions $(\mathrm{A}=$ microporosity and hot tears are absent, $\mathrm{B}=$ microporosity develops but hot tears do not form, and $\mathrm{C}=$ hot tears are formed) that give the conditions of strain rate and solid fraction. Cooling rates: $(a) 1 \mathrm{~K} / \mathrm{s}$ and $(b) 5 \mathrm{~K} / \mathrm{s}$.

which hot cracks are formed. Lowering the strain rate or cooling rate will increase the solid fraction at which hot tears start to develop. At certain strain rates, the hot tear will not develop.

In Figure 8, the boundaries of three regions are given as a function of the strain rate and solid fraction for the cooling rates 1 or $5 \mathrm{~K} / \mathrm{s}$. In region $\mathrm{A}, \partial f_{v} / \partial t$ equals zero or negative and, consequently, no microporosity or hot tears are developed. In region $\mathrm{B}, \partial f_{v} / \partial t$ is positive but $a$ is smaller than $a_{\text {crit }}$. Only microporosity will develop. Region $\mathrm{C}$, in which $a$ is larger than $a_{\text {crit }}$, marks the conditions for which hot tearing will occur. The beginning of the formation of porosity or hot cracks increases with the strain rate and cooling rate. 


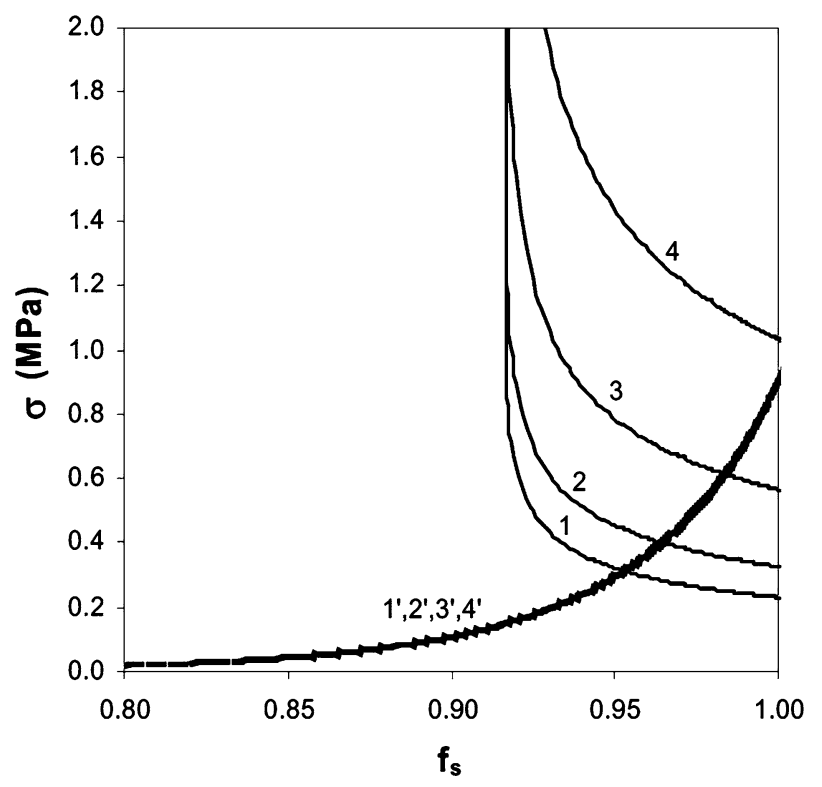

Fig. 9-Effect of grain size on the developed stress in the mush $\left(1^{\prime}\right.$ through $\left.4^{\prime}\right)$ and the critical stress (1 through 4$)$. Strain rates: $10^{-4} \mathrm{~s}^{-1}$. Grain diameters: $\left(1,1^{\prime}\right) 600 \mu \mathrm{m},\left(2,2^{\prime}\right) 300 \mu \mathrm{m},\left(3,3^{\prime}\right) 100 \mu \mathrm{m}$, and $\left(4,4^{\prime}\right) 30 \mu \mathrm{m}$.

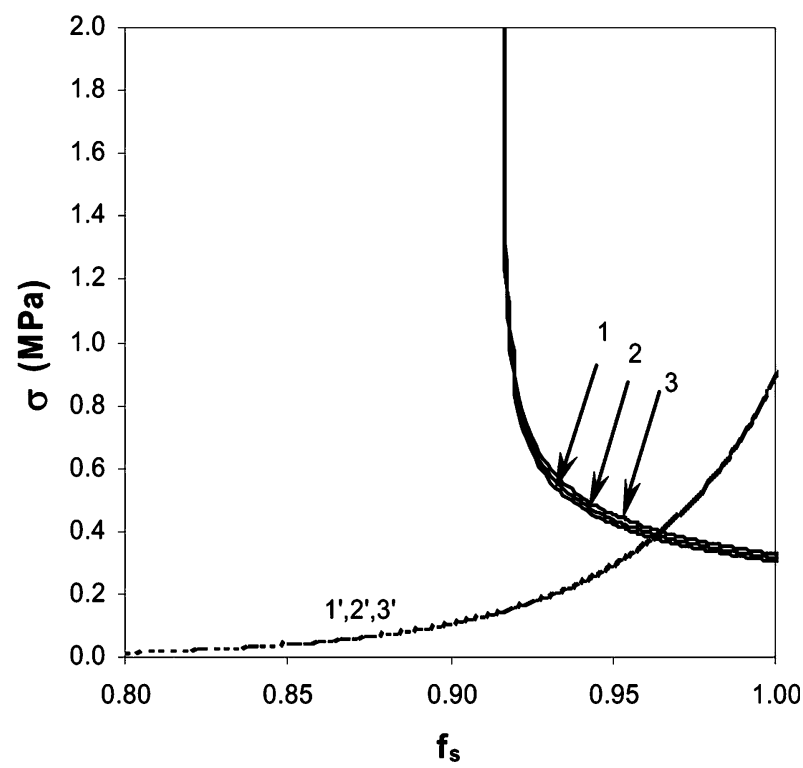

Fig. 10-Effect of packing parameter on the developed stress in the mush ( $1^{\prime}$ through $\left.3^{\prime}\right)$ and the critical stress (1 through 3$)$. Strain rate: $10^{-4} \mathrm{~s}^{-1}$. Packing parameters: $\left(1,1^{\prime}\right) 2.83,\left(2,2^{\prime}\right) 2.34$, and $\left(3,3^{\prime}\right) 1.85$.

\section{Effect of grain size and packing parameter}

The effect of the grain size on the developed stress in the mush and the critical stress is shown in Figure 9. It is found that a smaller size reduces the developed stress (and hot-tearing tendency) and that, below a certain grain size, a hot tear will not develop.

In Figure 10, the effect of the packing parameter on the developed stress in the mush and the critical stress is shown. The packing parameter hardly influences the stress or the location of the intersection points.

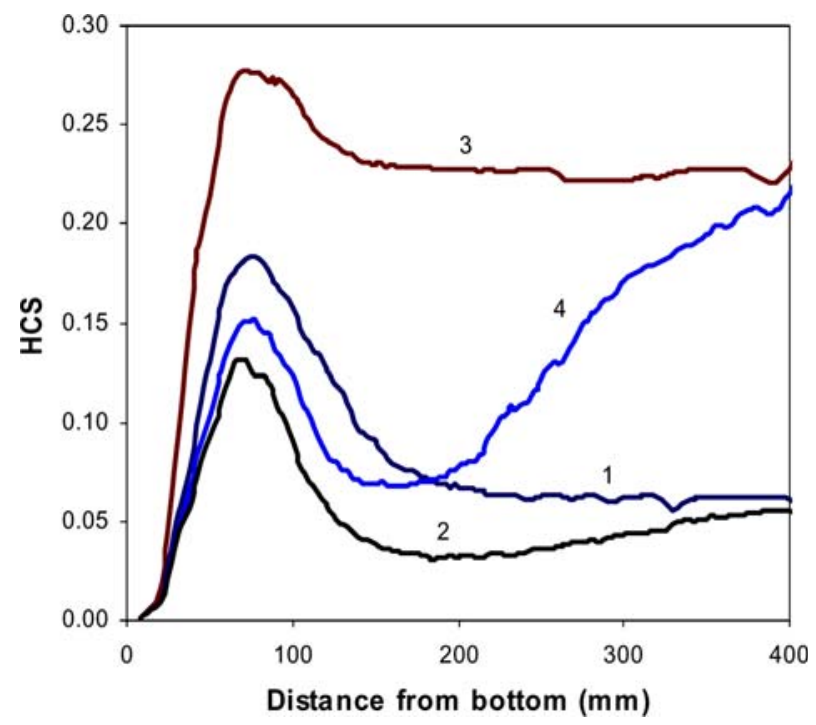

Fig. 11-HCS as a function of distance from the bottom block for the four casting conditions.

\section{B. Incorporation in FEM Simulation of DC Casting Billet}

In the simulation studies of the DC casting of a billet, the emphasis was on the calculation of the HCS as a function of various parameters. Here, the approach taken was similar to that used in an earlier study, in assessing several hot-tearing criteria in literature. ${ }^{[10]}$

\section{Start-up phase}

Figure 11 shows the hot-tearing susceptibility for the various casting conditions during startup. The susceptibility is maximum approximately $70 \mathrm{~mm}$ from the bottom of the billet. Using a ramping procedure reduces the susceptibility, although it does not influence its steady-state value. The hot-cracking sensitivity is higher for the higher casting rate. Because the HCS value is smaller than 1, a hot tear will not form.

In Figure 12, the development during solidification of the HCS $50 \mathrm{~mm}$ from the bottom of the billet is shown. The susceptibility increases with the solid fraction. A hot crack will not form.

\section{Steady-state phase}

Susceptibilities are considered steady state $750 \mathrm{~mm}$ from the bottom of the billet. The effect of the casting speed on the HCS in the steady state is shown in Figure 13 as a function of the distance from the center of the billet. The susceptibilities increase with increasing casting speed and are maximum in the center of the billet. At a distance of approximately $70 \mathrm{~mm}$ and higher from the center, the susceptibility is close to zero. In addition, for a casting speed of $180 \mathrm{~mm} / \mathrm{s}$, the susceptibility will be lower than 1 a hot crack will not form. The development of the susceptibility during solidification is shown in Figure 14. The values of the susceptibility start to deviate from zero level at a certain fraction solid that is dependent on the casting speed. The higher the casting speed, the lower the solid fraction for which the value deviates from zero. 


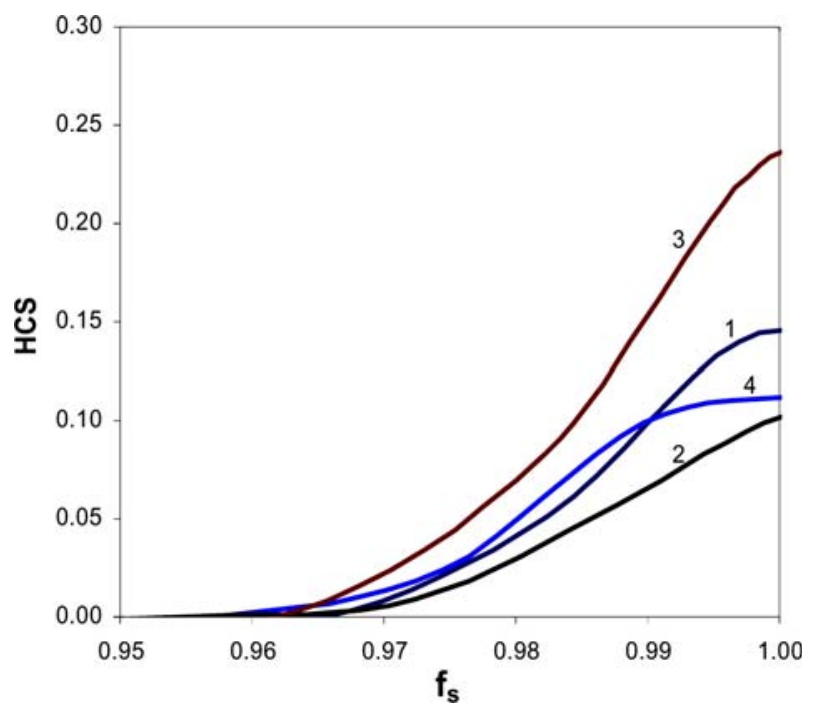

Fig. 12-HCS in the last stage of solidification $50 \mathrm{~mm}$ from the bottom.

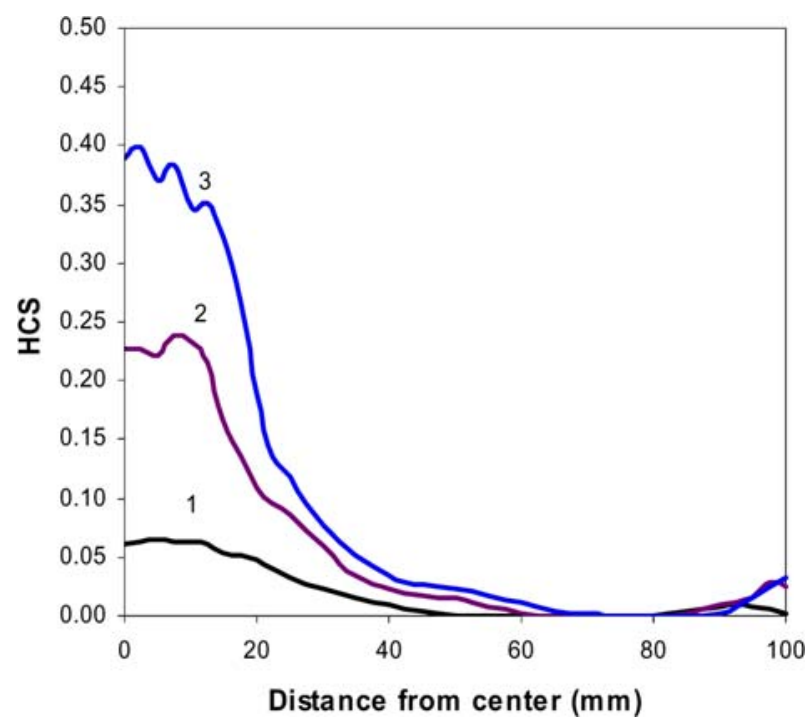

Fig. 13-HCS as a function of distance from the center of the billet. Casting speeds: (1) $120 \mathrm{~mm} / \mathrm{min}$, (2) $150 \mathrm{~mm} / \mathrm{min}$, and (3) $180 \mathrm{~mm} / \mathrm{min}$.

Because the Young's modulus at semisolid temperature is not well known, the effect of the Young's modulus on the HCS is shown in Figure 15. A higher Young's modulus will reduce the HCS.

The effect of the grain size on the HCS is shown in Figure 16. An increasing grain size will result in an increasing HCS, which is relevant for the center of the billet.

\section{DISCUSSION}

\section{A. Assumptions in the Presented Model}

In an assessment study ${ }^{[10]}$ of various criteria for hot cracking that were integrated into a FEM simulation

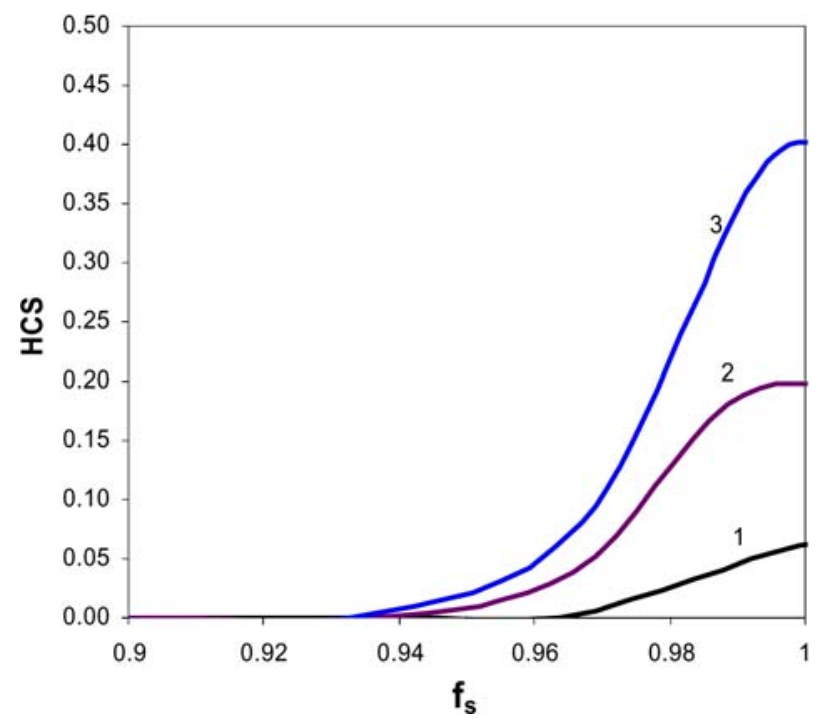

Fig. 14-HCS development during the last stage of solidification at casting speeds: (1) $120 \mathrm{~mm} / \mathrm{min}$, (2) $150 \mathrm{~mm} / \mathrm{min}$, and (3) $180 \mathrm{~mm} / \mathrm{min}$.

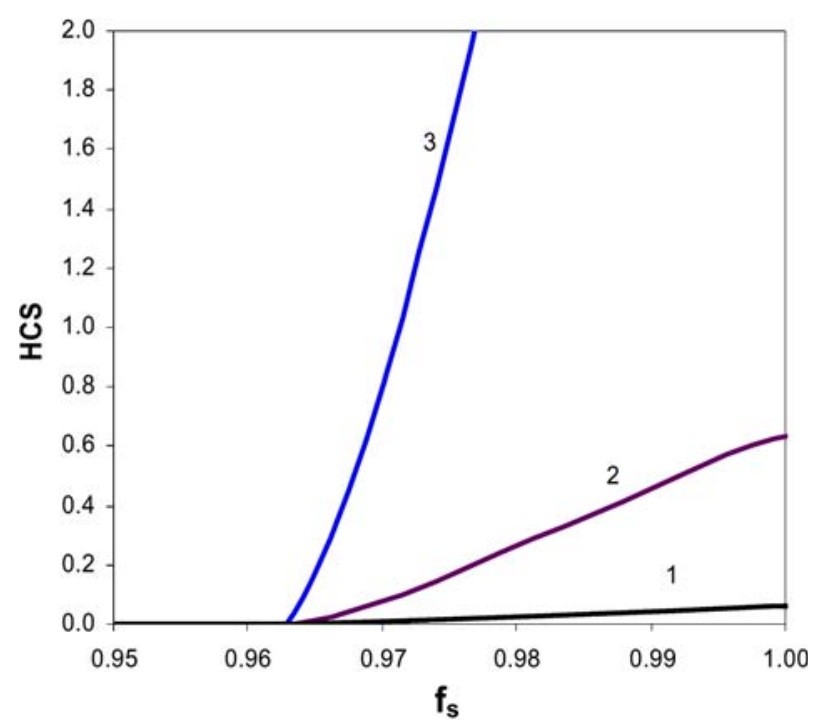

Fig. 15-HCS development during the last stage of solidification Young's modulus: (1) $10 \mathrm{GPa}$, (2) $1 \mathrm{GPa}$, and (3) $0.1 \mathrm{GPa}$. Center of billet. Casting speed: $120 \mathrm{~mm} / \mathrm{min}$.

and applied to DC casting, it is found that the RDG criterion, ${ }^{[19]}$ which combines aspects of mechanical as well as feeding conditions, had the greatest potential but did predict cracking for the practical conditions in which cracking will not occur. In the present model, several approaches and assumptions differ from those in the RDG model.

In both models, the basic equation is that of mass conservation; in the RDG approach, however, it is taken as steady state, whereas in the present approach it is transient, allowing for the formation of a cavity volume. The RDG considers the mass balance equation, whereas in the present model, the equation is strain based. In the RDG, feeding follows the shrinkage and gives rise to a 


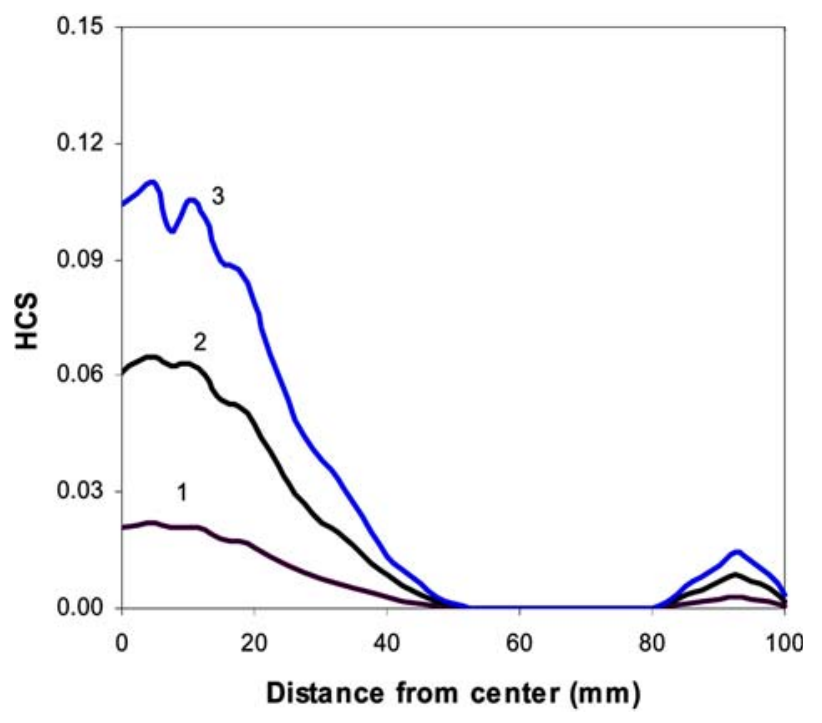

Fig. 16- HCS as a function of the distance from the center. Grain sizes: (1) $100 \mu \mathrm{m}$, (2) $300 \mu \mathrm{m}$, and (3) $500 \mu \mathrm{m}$. Casting speed: $120 \mathrm{~mm} / \mathrm{min}$.

pressure drop that may become critical. In the RDG approach, a crack is formed if the pressure drop becomes so high that the pressure in the liquid of the mush becomes lower than a critical pressure for cavity formation. For such a case, a cavity will form that always gives rise to the formation of a hot tear. In the present approach, a cavity will grow if the volume that can be fed per unit time becomes smaller than the volume change due to shrinkage and deformation. A cavity will lead to porosity, and only when its size will surpass a critical size will a crack be formed. Considering the mush as brittle, the critical size is determined from the Griffith approach ${ }^{[21]}$ and depends on the stress in the mush. It becomes smaller for higher stresses. Other differences are that the RDG considers a columnar solidification structure, whereas the present model assumes an equiaxed structure, such as is commonly found in DC-cast billets, and that the RDG is essentially a two-dimensional approach, whereas the present model is, in principle, $3-\mathrm{D}$.

\section{B. Observations with Constant Parameter Simulations}

As Figure 8 demonstrates, the formation of porosity or hot cracks is promoted by higher strain rates and higher cooling rates. These observations are in line with those found by other authors. ${ }^{[19,33]}$ The observation that smaller grain sizes reduce the tendency for porosity or hot tearing (Figure 9) is confirmed by References 27 through 29 and is supported by the beneficial effect of the addition of grain refiners. Figure 8 indicates that, during the last stage of solidification, porosity is always formed. The model not only indicates whether porosity will be found but also predicts the amount of porosity. Stresses in the mush at which hot tears are formed (Figures 5, 6,9, and 10) are in the range of 0.1 to $2 \mathrm{MPa}$. These values are in agreement with the fracture stresses found in the tensile tests of semisolid aluminum alloys. ${ }^{[30-32]}$
The hot-tearing sensitivities presented in Figures 5(b) and 6(b) also indicate increasing sensitivity for an increasing strain rate or increasing cooling rate. For all the strain rates and cooling rates applied here, the HCS value becomes higher than 1, which means that hot cracking will take place. However, some parameters used in these calculations (for example, the Young's modulus) are rather uncertain and have a significant influence on the HCS value. For the Young's modulus, we did use in these calculations the only value known to us, ${ }^{[20,33]}$ but we believe that a higher value might be more realistic, one that predicts that cracks are not formed for some of the strain rate and cooling rate parameters, which is more in agreement with industrial practice.

\section{Observations with DC-Cast Simulations}

Incorporation of the model into a FEM simulation leads to results comparable to those obtained with the simulations with constant parameters. The HCS increases with the casting speed and is maximum in the center of the billet. It is higher for a larger grain size.

The FEM simulation also shows (Figure 11) that the susceptibility at approximately $80 \mathrm{~mm}$ from the bottom is highest and that it reduces when the casting speed is lowered. It means that the application of a ramping procedure during the start-up phase has significance.

In Figures 17 and 18, the hot-cracking susceptibilities obtained in this study are compared with the depression pressures (which are a measure for HCS), obtained in an earlier study ${ }^{[10]}$ with the RDG model. ${ }^{[19]}$ The conditions used in the simulation were identical. It is seen that shapes of the corresponding curves are rather similar; therefore, in the qualitative sense, there is not much difference between the predictions for the RDG model and for the present model.

In the RDG model, depression pressures exceeding a critical value will lead to the formation of a hot crack. As a critical value, a value of $2 \mathrm{kPa}$ is given. ${ }^{[5]}$ The depression pressures in Figures 17 and 18 are considerably higher and will therefore always lead to the formation of a hot crack.

In the present model, HCS values lower than 1 will not lead to the formation of a hot crack and it is seen that, for the conditions simulated here, a hot crack will not be formed.

In Reference 10, we assessed several hot-cracking criteria on their predictive capability of four major observations in industrial experience. In Table III, a similar assessment is done with the present model. It is seen that the predictive capability of the present model is excellent on these four issues. A full quantitative assessment should require detailed casting trials and an independent determination of the Young's modulus in the mushy state.

\section{Present Limitations}

Validation of the model should take place in direct comparison with actual casting trials. In this validation, some model parameters are more critical or less known 


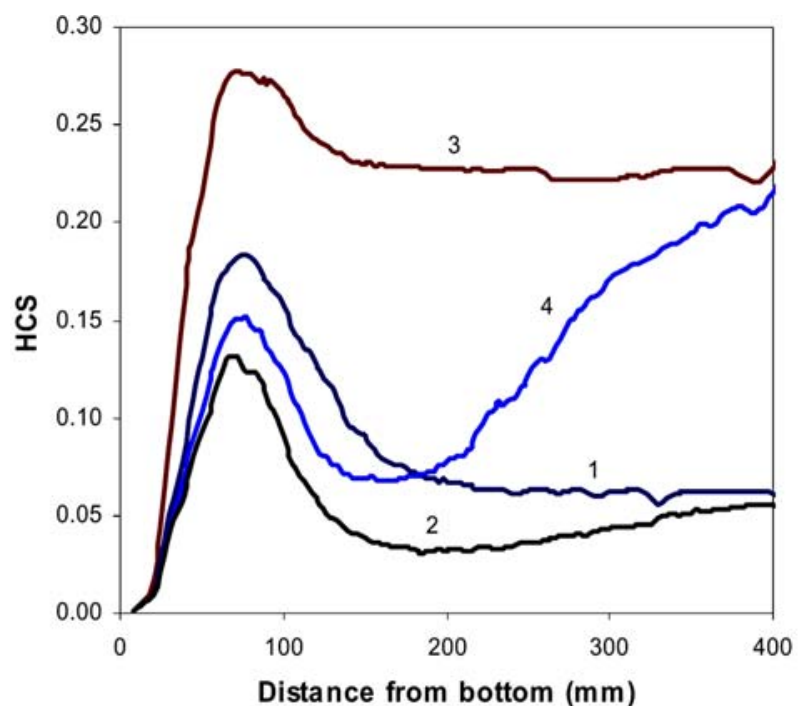

(a)

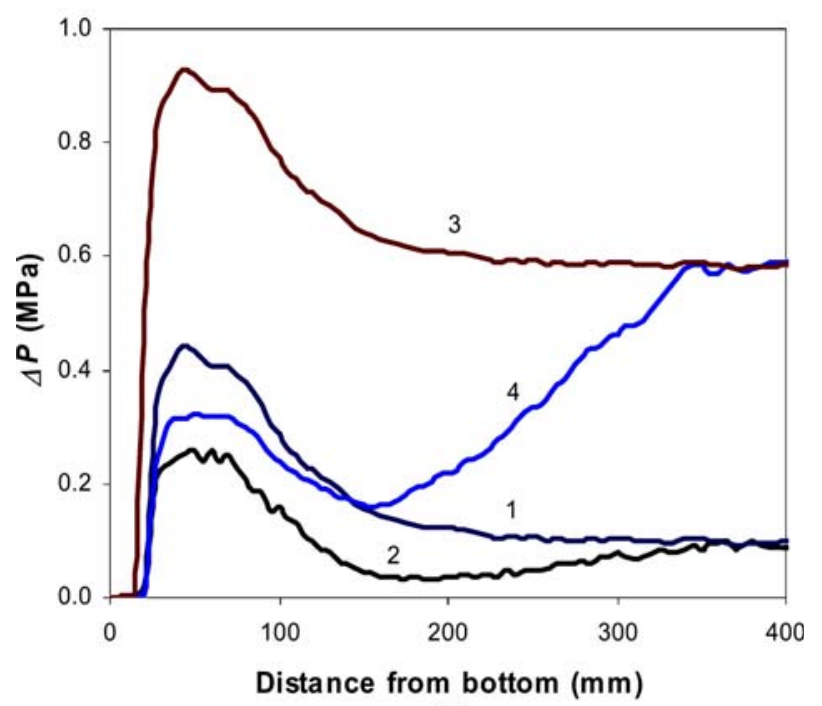

(b)

Fig. 17- (a) HCS and (b) depression pressure as a function of distance from the bottom block for the four casting conditions.

than others. Let us assume, as has been done in this study, a constant strain rate and a constant cooling rate. For the calculation of the fraction solid in which porosity starts to appear, we set $|f e|$ equal to $f r$ and, using Eqs. [4] through [8], we derive the following equation:

$$
\begin{aligned}
& K \lambda^{2}\left(1-f_{s}\right)^{2} \\
& \quad=\frac{\eta L^{2} f_{l}^{2}}{\left(P_{o}+P_{m}-\frac{4 \gamma_{s}}{\lambda}\right)}\left[\left(1-\frac{\rho_{s}}{\rho_{l}}\right) \frac{\partial f_{l}}{\partial T} \frac{\partial T}{\partial t}+\left(\frac{\rho_{s}}{\rho_{l}}\right) \dot{\varepsilon}_{k}\right]
\end{aligned}
$$

The expression at the left side is related to the amount of porosity found after casting (in case hot tears are absent). At the right side, the parameters $L$ and $\partial f_{l} / \partial T$ are well known or can easily be determined. Parameter

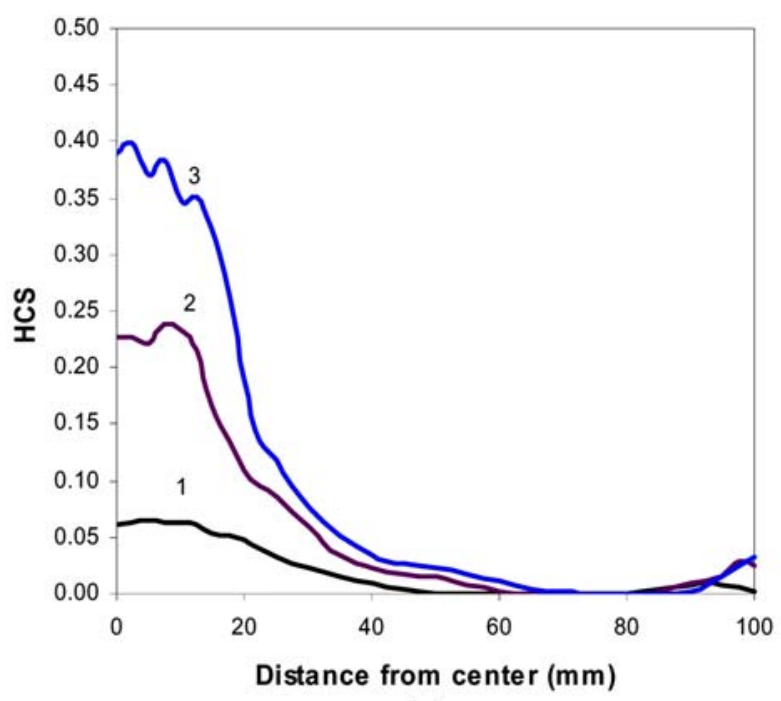

(a)

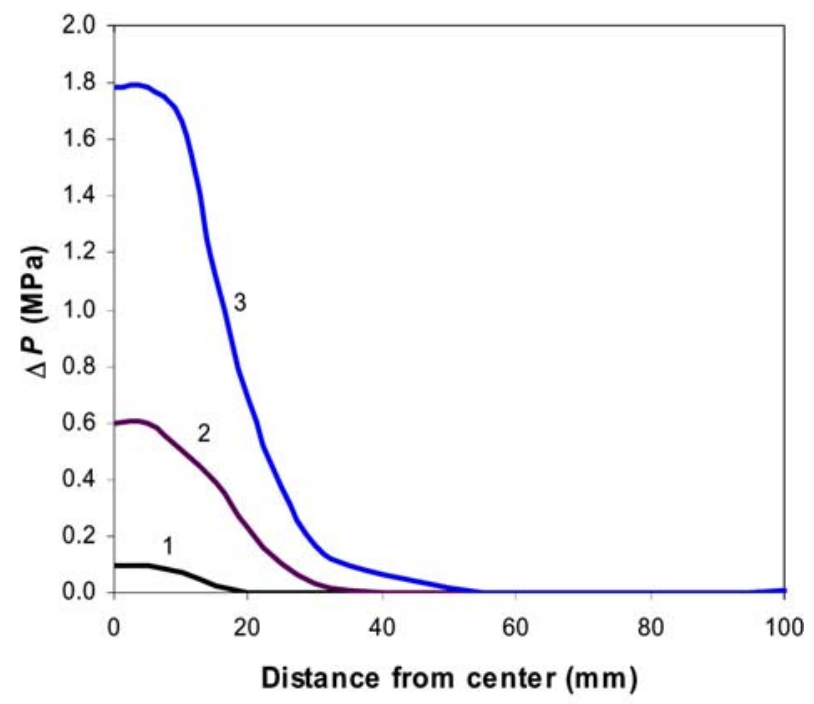

(b)

Fig. 18 - (a) HCS and (b) depression pressure as a function of distance from the center of the billet. Casting speeds: (1) $120 \mathrm{~mm} / \mathrm{min}$, (2) $150 \mathrm{~mm} / \mathrm{min}$, and (3) $180 \mathrm{~mm} / \mathrm{min}$.

Table III. Predictive Capability of the Model on Four Major Observations

\begin{tabular}{lccc}
\hline Observation & Practice & Prediction \\
\hline A & $\begin{array}{c}\text { increasing sensitivity } \\
\text { for higher casting speed }\end{array}$ & yes & yes \\
B & $\begin{array}{c}\text { highest sensitivity in billet } \\
\text { center }\end{array}$ & yes & yes \\
C & $\begin{array}{c}\text { ramping might have positive } \\
\text { effect }\end{array}$ & yes & yes \\
D & crack will be formed & no & no \\
\hline
\end{tabular}

$4 \gamma_{s} / \lambda$ is relatively small compared with $P_{0}+P_{m}$, so its influence on the porosity is relatively low. At the left side, the permeability of the mush $K$ is a critical parameter in determining when porosity starts to form 
and the final amount obtained. However, the value of $K$ is relatively uncertain and is also difficult to determine. Therefore, regarding porosity, the permeability is the main parameter under consideration for possible adjustment in a validation experiment.

For the determination of when a hot crack starts to appear, we derive the following equation from Eqs. [11] through [14]:

$$
f_{v}=\left[\frac{4 \gamma_{s} E}{\pi \sigma^{2}} \frac{1}{C_{1} d_{g}}\left(\frac{2 \pi}{3 C}\right)^{1 / 3}\right]^{3}
$$

If $f_{v}$ is smaller than the right-side term, a hot tear will not be formed, whereas if $f_{v}$ is higher, a hot tear will form. The various parameters at the right side are $d_{g}$, which can be experimentally determined, and $C, C_{1}, \gamma_{s}$, $E$, and stress $\sigma$ in mush. The parameter combination $\left(\gamma_{s} \cdot E / \sigma^{2} \cdot C_{1} \cdot C^{1 / 3}\right)$ is dominant in the formation of hot cracks and is therefore the main expression under consideration for possible adjustment in a validation experiment. The most unknown parameter is assumed to be the Young's modulus $E$, which is difficult to determine because of the low strength and high brittleness of the mush. The data in the literature on the Young's modulus of a mush are scarce. The value in the study with the constant parameters is taken from References 20 and 33. The value taken in the simulation with DC casting is higher, in order to be more in agreement with the results in actual casting experiments.

\section{CONCLUSIONS}

A model is proposed for prediction of the formation of microporosity and hot tears during DC casting. It assumes that volume changes during solidification resulting from the mechanical conditions should be fed by liquid. If feeding is insufficient, a cavity volume is formed. A new element in the model is that the formation of a cavity leads to microporosity and that if its size exceeds a certain critical size, a hot crack will form. The mush is considered brittle and therefore the critical size is derived from fracture mechanics. The model shows features well known from the literature such as increasing susceptibility for microporosity formation and hot tearing with increasing deformation rate, increasing cooling rate (i.e., increasing casting speed), and increasing grain size. The model also indicates a higher sensitivity in the billet center. After incorporating this model in an FEM simulation for a DC casting billet, these observations are not only confirmed, but it is also found that the application of a ramping procedure during the start-up phase might give a beneficial effect. As such, the present model improves the results found in an earlier assessment study based on the criteria known from the literature. Further, in this study, key parameters are identified for which the values are rather uncertain and which may therefore act as fitting parameters in a validation study.

\section{OPEN ACCESS}

This article is distributed under the terms of the Creative Commons Attribution Noncommercial License which permits any noncommercial use, distribution, and reproduction in any medium, provided the original author(s) and source are credited.

\section{APPENDIX}

The derivation of Eq. [3] uses the conservation of mass equation based upon the general framework for the volume averaged conservation equation as presented in Reference 34.

$$
\begin{gathered}
\frac{\partial\left(f_{s} \rho_{s}\right)}{\partial t}+\nabla \cdot\left(f_{s} \rho_{s} v_{s}\right)=\Gamma \\
\frac{\partial\left(f_{l} \rho_{l}\right)}{\partial t}+\nabla \cdot\left(f_{l} \rho_{l} v_{l}\right)=-\Gamma
\end{gathered}
$$

where $f_{n}$ is the volume fraction of phase $n(n=s, l$, and $v$ for the solid, liquid, and cavity, respectively), $\rho_{k}$ denotes the mass density, $v_{k}$ is the velocity, and $\Gamma$ is the interfacial mass transfer due to phase change.

Adding Eqs. [A1] and [A2] gives the mass conservation equation for the two-phase (solid-liquid) system:

$$
\begin{gathered}
\frac{\partial\left(f_{s} \rho_{s}\right)}{\partial t}+\frac{\partial\left(f_{l} \rho_{l}\right)}{\partial t}+\nabla \cdot\left(f_{s} \rho_{s} v_{s}\right)+\nabla \cdot\left(f_{l} \rho_{l} v_{l}\right)=0 \\
\frac{\partial\left(f_{s} \rho_{s}\right)}{\partial t}=f_{s} \frac{\partial \rho_{s}}{\partial t}+\rho_{s} \frac{\partial f_{s}}{\partial t} \\
\frac{\partial\left(f_{l} \rho_{l}\right)}{\partial t}=f_{l} \frac{\partial \rho_{l}}{\partial t}+\rho_{l} \frac{\partial f_{l}}{\partial t} \\
\nabla \cdot\left(f_{s} \rho_{s} v_{s}\right)=\frac{\partial}{\partial x}\left(f_{s} \rho_{s} v_{x, s}\right)+\frac{\partial}{\partial y}\left(f_{s} \rho_{s} v_{y, s}\right)+\frac{\partial}{\partial z}\left(f_{s} \rho_{s} v_{z, s}\right)
\end{gathered}
$$

$$
\begin{gathered}
\frac{\partial}{\partial x}\left(f_{s} \rho_{s} v_{x, s}\right)=\rho_{s} \frac{\partial}{\partial x}\left(f_{s} v_{x, s}\right)+f_{s} v_{x, s} \frac{\partial}{\partial x}\left(\rho_{s}\right) \\
\frac{\partial}{\partial y}\left(f_{s} \rho_{s} v_{y, s}\right)=\rho_{s} \frac{\partial}{\partial y}\left(f_{s} v_{y, s}\right)+f_{s} v_{y, s} \frac{\partial}{\partial y}\left(\rho_{s}\right) \\
\frac{\partial}{\partial z}\left(f_{s} \rho_{s} v_{z, s}\right)=\rho_{s} \frac{\partial}{\partial z}\left(f_{s} v_{z, s}\right)+f_{s} v_{z, s} \frac{\partial}{\partial z}\left(\rho_{s}\right) \\
\nabla \cdot\left(f_{l} \rho_{l} v_{l}\right)=\frac{\partial}{\partial x}\left(f_{l} \rho_{l} v_{x, l}\right)+\frac{\partial}{\partial y}\left(f_{l} \rho_{l} v_{y, l}\right)+\frac{\partial}{\partial z}\left(f_{l} \rho_{l} v_{z, l}\right)
\end{gathered}
$$

$$
\frac{\partial}{\partial x}\left(f_{l} \rho_{l} v_{x, l}\right)=\rho_{l} \frac{\partial}{\partial x}\left(f_{l} v_{x, l}\right)+f_{l} v_{x, l} \frac{\partial}{\partial x}\left(\rho_{l}\right)
$$




$$
\begin{aligned}
\frac{\partial}{\partial y}\left(f_{l} \rho_{l} v_{y, l}\right) & =\rho_{l} \frac{\partial}{\partial y}\left(f_{l} v_{y, l}\right)+f_{l} v_{y, l} \frac{\partial}{\partial y}\left(\rho_{l}\right) \\
\frac{\partial}{\partial z}\left(f_{l} \rho_{l} v_{z, l}\right) & =\rho_{l} \frac{\partial}{\partial z}\left(f_{l} v_{z, l}\right)+f_{l} v_{z, l} \frac{\partial}{\partial z}\left(\rho_{l}\right)
\end{aligned}
$$

Substitution of Eqs. [A4a], [A4b], and [A5a] through [A5h] to Eq. [A3] yields

$$
\begin{aligned}
f_{s} \frac{\partial \rho_{s}}{\partial t}+\rho_{s} \frac{\partial f_{s}}{\partial t}+f_{l} \frac{\partial \rho_{l}}{\partial t}+\rho_{l} \frac{\partial f_{l}}{\partial t}+\rho_{s} \frac{\partial}{\partial x}\left(f_{s} v_{x, s}\right)+f_{s} v_{x, s} \frac{\partial}{\partial x}\left(\rho_{s}\right) \\
+\rho_{s} \frac{\partial}{\partial y}\left(f_{s} v_{y, s}\right)+f_{s} v_{y, s} \frac{\partial}{\partial y}\left(\rho_{s}\right)+\rho_{s} \frac{\partial}{\partial z}\left(f_{s} v_{z, s}\right)+f_{s} v_{z, s} \frac{\partial}{\partial z}\left(\rho_{s}\right) \\
+\rho_{l} \frac{\partial}{\partial x}\left(f_{l} v_{x, l}\right)+f_{l} v_{x, l} \frac{\partial}{\partial x}\left(\rho_{l}\right)+\rho_{l} \frac{\partial}{\partial y}\left(f_{l} v_{y, l}\right)+f_{l} v_{y, l} \frac{\partial}{\partial y}\left(\rho_{l}\right) \\
+\rho_{l} \frac{\partial}{\partial z}\left(f_{l} v_{z, l}\right)+f_{l} v_{z, l} \frac{\partial}{\partial z}\left(\rho_{l}\right)=0 \\
1=f_{l}+f_{s}+f_{v} \\
f_{s}=1-f_{l}-f_{v} \\
\frac{\partial f_{s}}{\partial t}=-\frac{\partial f_{l}}{\partial t}-\frac{\partial f_{v}}{\partial t}
\end{aligned}
$$

Substitution of Eq. [A9] into Eq. [A6] and division by $\rho_{l}$ yields

$$
\begin{gathered}
\frac{f_{s}}{\rho_{l}} \frac{\partial \rho_{s}}{\partial t}-\frac{\rho_{s}}{\rho_{l}} \frac{\partial f_{l}}{\partial t}-\frac{\rho_{s}}{\rho_{l}} \frac{\partial f_{v}}{\partial t}+\frac{f_{l}}{\rho_{l}} \frac{\partial \rho_{l}}{\partial t}+\frac{\partial f_{l}}{\partial t}+\frac{\rho_{s}}{\rho_{l}} \frac{\partial}{\partial x}\left(f_{s} v_{x, s}\right) \\
+\frac{f_{s} v_{x, s}}{\rho_{l}} \frac{\partial}{\partial x}\left(\rho_{s}\right)+\frac{\rho_{s}}{\rho_{l}} \frac{\partial}{\partial y}\left(f_{s} v_{y, s}\right)+\frac{f_{s} v_{y, s}}{\rho_{l}} \frac{\partial}{\partial y}\left(\rho_{s}\right) \\
+\frac{\rho_{s}}{\rho_{l}} \frac{\partial}{\partial z}\left(f_{s} v_{z, s}\right)+\frac{f_{s} v_{z, s}}{\rho_{l}} \frac{\partial}{\partial z}\left(\rho_{s}\right)+\frac{\partial}{\partial x}\left(f_{l} v_{x, l}\right) \\
+\frac{f_{l} v_{x, l}}{\rho_{l}} \frac{\partial}{\partial x}\left(\rho_{l}\right)+\frac{\partial}{\partial y}\left(f_{l} v_{y, l}\right)+\frac{f_{l} v_{y, l}}{\rho_{l}} \frac{\partial}{\partial y}\left(\rho_{l}\right) \\
+\frac{\partial}{\partial z}\left(f_{l} v_{z, l}\right)+\frac{f_{l} v_{z, l}}{\rho_{l}} \frac{\partial}{\partial z}\left(\rho_{l}\right)=0
\end{gathered}
$$

Assuming that $\rho_{l}$ and $\rho_{s}$ are constant gives

$$
\begin{aligned}
- & \frac{\rho_{s}}{\rho_{l}} \frac{\partial f_{l}}{\partial t}-\frac{\rho_{s}}{\rho_{l}} \frac{\partial f_{v}}{\partial t}+\frac{\partial f_{l}}{\partial t}+\frac{\rho_{s}}{\rho_{l}} \frac{\partial}{\partial x}\left(f_{s} v_{x, s}\right)+\frac{\rho_{s}}{\rho_{l}} \frac{\partial}{\partial y}\left(f_{s} v_{y, s}\right) \\
& +\frac{\rho_{s}}{\rho_{l}} \frac{\partial}{\partial z}\left(f_{s} v_{z, s}\right)+\frac{\partial}{\partial x}\left(f_{l} v_{x, l}\right)+\frac{\partial}{\partial y}\left(f_{l} v_{y, l}\right)+\frac{\partial}{\partial z}\left(f_{l} v_{z, l}\right)=0
\end{aligned}
$$

Rearrangement of terms in Eq. [A11] gives

$$
\frac{\rho_{s}}{\rho_{l}} \frac{\partial f_{v}}{\partial t}=-\left(\frac{\rho_{s}}{\rho_{l}}-1\right) \frac{\partial f_{l}}{\partial t}+\frac{\rho_{s}}{\rho_{l}} \dot{\varepsilon}+f e
$$

where $\dot{\varepsilon}$ is the strain rate and $f e$ is the feeding rate.

\section{REFERENCES}

1. D.G. Eskin, Suyitno, and L. Katgerman: Prog. Mater. Sci., 2004, vol. 49 , pp. 629-711.

2. I. Farup and A. Mo: Metall. Mater. Trans. A, 2000, vol. 31A, pp. 1461-72.

3. M. M'Hamdi, A. Mo, and C.L. Martin: Metall. Mater. Trans. A, 2002, vol. 33A, pp. 2081-95.

4. Suyitno, W.H. Kool, and L. Katgerman: Metall. Mater. Trans. A, 2004, vol. 35A, pp. 2917-26.

5. J.M. Drezet and M. Rappaz: in Light Metals 2001, J.L. Anjier, ed., TMS, Warrendale, PA, 2001, pp. 887-93.

6. J.M. Drezet, M. M'Hamdi, S. Benum, D. Mortensen, and H. Fjaer: Mater. Sci. Forum, 2002, vols. 396-402, pp. 59-64.

7. M. M'Hamdi, S. Benum, D. Mortensen, H. Fjaer, and J.M. Drezet: Metall. Mater. Trans. A, 2003, vol. 34A, pp. 1941-52.

8. Suyitno, W.H. Kool, and L. Katgerman: in Light Metals 2003, P.N. Crepeau, ed., TMS, Warrendale, PA, 2003, pp. 753-58.

9. Suyitno, D.G. Eskin, V.I. Savran, and L. Katgerman: Metall. Mater. Trans. A, 2004, vol. 35A, pp. 3551-61.

10. Suyitno, W.H. Kool, and L. Katgerman: Metall. Mater. Trans. A, 2005, vol. 36A, pp. 1537-46.

11. Suyitno, D.G. Eskin, and L. Katgerman: Mater. Sci. Eng., A, 2006, vol. 420, pp. 1-7.

12. D.G. Eskin and L. Katgerman: Metall. Mater. Trans. A, 2008, vol. $38 \mathrm{~A}$, pp. $1511-19$.

13. U. Feurer: Quality Control of Engineering Alloys and the Role of Metals Science, Delft University of Technology, Delft, The Netherlands, 1977, pp. 131-35.

14. T.W. Clyne and G.J. Davies: Br. Foundryman, 1981, vol. 74, pp. 65-69.

15. L. Katgerman: J. Met., 1982, vol. 34 (2), pp. 46-49.

16. N.N. Prokhorov: Russ. Cast. Prod., 1962, vol. 2, pp. 172-75.

17. I.I. Novikov: Goryachelomkost Tsvetnykh Metallov i Splavov (Hot Shortness of Non-Ferrous Metals and Alloys), Nauka, Moscow, 1966 (in Russian).

18. B. Magnin, L. Katgerman, and B. Hannart: in Modeling of Casting Welding and Advanced Solidification Processes VII, M. Cross and J. Campbell, eds., TMS, Warrendale, PA, 1995, pp. 303-10.

19. M. Rappaz, J.-M. Drezet, and M. Gremaud: Metall. Mater. Trans. A, 1999, vol. 30A, pp. 449-55.

20. M. Braccini, C.L. Martin, and M. Suery: in Modelling of Casting Welding and Advanced Solidification Processes IX, P.R. Sahm, P.N. Hansen, and J.G. Conley, eds., Shaker Verlag, Aachen, Germany, 2000, pp. 18-24.

21. A.A. Griffith: Philos. Trans. R. Soc. London, 1920, vol. A221, pp. 163-67.

22. A.A. Griffith: Proc. 1st Int. Cong. for Applied Mechanics, C.B. Biezeno and J.M. Burgers, eds., Waltman, Delft, The Netherlands, 1924, pp. 55-58

23. B. Commet, P. Delaire, J. Rabenberg, and J. Storm: in Light Metals 2003, P.N. Crepeau, ed., TMS, Warrendale, PA, 2003, pp. 711-17.

24. W. Kurz and D.J. Fisher: Fundamentals of Solidification, Trans Tech Publications, Aedermannsdorf, Switzerland, 1992.

25. T.S. Piwonka and M.C. Flemings: Trans. AIME, 1966, vol. 236, pp. $1157-65$

26. K. Kubo and R.D. Pehlke: Metall. Trans. B, 1985, vol. 16B, pp. 359-66.

27. J. Campbell: Castings, Butterworth, Oxford, United Kingdom, 1992.

28. W.S. Pellini: Foundry, 1952, vol. 80, pp. 124-33.

29. T.W. Clyne and G.J. Davies: Solidification and Casting of Metals, TMS, Warrendale, PA, 1979, pp. 275-78.

30. P. Ackermann and W. Kurz: Mater. Sci. Eng., 1985, vol. 75, pp. 79-86.

31. W.M. Van Haaften, W.H. Kool, and L. Katgerman: Mater. Sci. Forum, 2000, vols. 331-337, pp. 265-71.

32. P. Wisniewski: Doctoral Thesis, University of Pittsburgh, Pittsburgh, PA, 1990.

33. M. Suéry, C.L. Martin, M. Braccini, and Y. Bréchet: Adv. Eng. Mater., 2001, vol. 3 (8), pp. 589-91.

34. J. Ni and C. Beckermann: Metall. Trans. B, 1991, vol. 22B, pp. 349-61.

35. Y.S. Touloukian and E.H. Buyco: Thermophysical Properties of Matter, Vol. 4: Specific Heat, Metallic Elements and Alloys, IFI/ Plenum, New York, NY, 1970. 